\title{
The Impact of Fatigue on Daily Activity in People with Chronic Kidney Disease
}

Associate Professor Ann Bonner

School of Nursing, Midwifery \& Indigenous Health, Charles

Sturt University

Professor Sally Wellard

School of Nursing, University of Ballarat

Dr Marie Caltabiano

School of Psychology, James Cook University

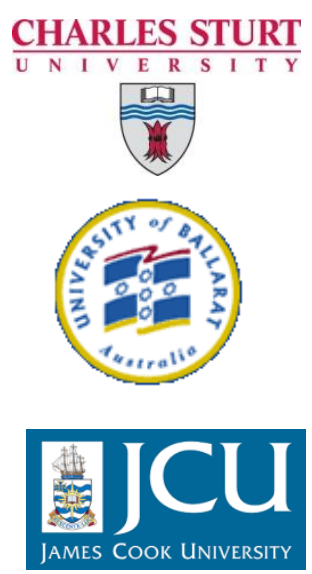


SCHOOL OF NURSING, MIDWIFERY \& INDIGENOUS HEALTH

\section{Presentation Outline}

- Background

- Research design

- Results

- Discussion

- Implications for nursing practice 


\section{Background}

- Physical fatigue is one of the most frequently experienced and troublesome symptoms with approximately $90 \%$ of patients reporting a lack of energy and feeling tired (Thomas-Hawkins 2000, Braun Curtin et al. 2002).

- People with CKD report a reduced capacity to engage in regular daily activities (Painter et al. 2000, Tawney et al. 2003) and difficulties with being able to undertake routine living activities (Periman et al. 2005). 


\section{Fatigue}

- Fatigue has been extensively examined in haemodialysis patient populations (McCann \& Boore 2000, Liu 2006, Lee et al. 2007).

- Few studies report the impact of fatigue on people with CKD regardless of the stage or type RRT (Bonner et al. 2008). 


\section{Activity}

- Physical activity has been extensively researched in haemodialysis patients (Johansen et al. 2000, Painter 2005).

- The level of activity amongst other RRT groups and at other stages of CKD is less well understood.

- There is also limited understanding of the level of activity among Australians with CKD. 
Study Aims:

1. Examine the impact of fatigue on the daily activity levels of people with CKD

2. Compare whether being pre-dialysis or receiving different renal replacement therapies had any effect on fatigue and activity

3. Identify if any items within the fatigue severity scale (FSS) were more predictive of daily activity levels 


\section{Research Design}

- Descriptive cross sectional design

- One renal unit

- Convenience sample

- CKD stages 4 \& 5

- Ethics approval 


\section{Data}

- Fatigue Severity Scale (FSS)

- Useful in measuring fatigue in chronic illnesses

-9 items

- Human Activity Profile (HAP)

- Useful to measure daily living activities

- Activities associated with personal hygiene, household duties through to high levels of physical exercise

-94 items 


\section{Results: Demographic}

- 112 participants $(45 \mathrm{~F}, 65 \mathrm{M})$

- $18-84$ yrs of age (mean = $55 \mathrm{yrs}$ )

- 64 non-indigenous, 48 indigenous

- Cause of renal failure

- $43(38 \%)$ diabetes

- $30(26.5 \%)$ GN

- 29 pre-dialysis, $42 \mathrm{HD}, 14 \mathrm{PD}, 27 \mathrm{Tx}$

- Length of time on RRT

-1 month to 21 years 


\section{Results: Demographic}

- Older people (> $65 \mathrm{yrs}$ ) were more fatigued and engaged in less physical activity $(F=6.34, \mathrm{dt}(4,107)$, $p<.0001$ )

- Women reported being more fatigued and engaged in less daily activity than men ( $F=4.83$, df $(3,108) p<.01)$

- Diabetics reported more fatigue and less activity $(F=2.71$, df $(6,105), p<.05)$ 


\section{Results: RRT \& Biochemistry}

- PD patients had higher fatigue and less activity levels $(\mathrm{F}=8.14$, df $(3,108), p<.0001)$

- No significant findings for length of time on RRT (either < or > 6 months; < or > 12 months)

- Comparing biochemistry $\left(\mathrm{K}, \mathrm{PO}_{4}\right)$ with fatigue and activity (NS)

- Pre-dialysis and PD patients with serum albumin $<40 \mathrm{~g} / \mathrm{L}$ had higher fatigue and least activity $(F=30.58$, df $(1,110), p<.001)$ 


\section{Results: Fatigue, Activity \& ESA}

- 69 patients prescribed an Erythropoietin Stimulating Agent (ESA).

- Prescribed an ESA were significantly more fatigued $[\mathrm{F}=10.77$, df $(1,110), \mathrm{p}<.01]$.

- Prescribed an ESA were significantly less active [F=18.67, df $(1,110), p<.001]$.

- $\mathrm{Hb}<110$ fatigue was much higher $[\mathrm{F}=3.4$, df $(1,109)$, $\mathrm{p}=.06]$.

- A trend for $\mathrm{Hb}<110$ to be less active (ns) 


\section{Results: Fatigue and Activity}

\begin{tabular}{|l|c|c|}
\hline HAP subscale & $\begin{array}{c}\text { Pearson } \\
\text { correlation } \\
\text { coefficient }\end{array}$ & Significance \\
\hline Self care & -.005 & .957 (n.s.) \\
\hline Personal/household work & -.394 & .0001 \\
\hline Entertainment/social & -.406 & .0001 \\
\hline Independent exercise & -.511 & .0001
\end{tabular}




\section{HAP items and Subscales}

Fatigue is among my three most disabling symptoms

Sweeping (5 min non-stop) .437

Walking 6 blocks on level ground (non-stop) .455

Walking one mile .421

Walking one mile (non-stop) .493

Walking two miles .537

Walking two miles (non-stop) .483

Total activity

$-.501$

Personal household work

$-.457$

Entertainment/social

$-.392$

Independent exercise

$-.484$

All correlations significant at $p<.001$ 


\section{Discussion}

- High levels of fatigue are experienced by people with CKD regardless of whether they are predialysis or receiving haemodialysis or peritoneal dialysis.

- Regardless of the length of time on RRT (even as little as 1 month) people experience high fatigue and low activity levels.

- Fatigue influences their ability to engage in daily activities including independent exercise. 


\section{Implications for Practice}

- Early identification and regular monitoring of both fatigue and activity levels.

- Educational strategies that highlight the increased risks

- Closely monitor albumin levels and refer patients for specialist dietetic support to avoid these risks.

- Incorporate rehabilitative strategies which aim to reduce fatigue and maximise activity levels. 


\section{Conclusion}

CKD causes people to be highly fatigued and affects their capacity to:

- perform routine living activities such housework, shopping, etc

- participate in and enjoy everyday life

- undertake exercise 


\section{Questions}

Acknowledgements

- Patients who participated

- James Cook University research funding 


\section{References}

Bonner A, Wellard S \& Caltabiano M (2008) Levels of fatigue in people with ESRD living in Far North Queensland. Journal of Clinical Nursing 17, 90-98.

Bonner A, Wellard S \& Caltabiano M (In press) The impact of fatigue on daily activity in people with chronic kidney disease. Journal of Clinical Nursing.

Braun Curtin R, Bultman DC, Thomas-Hawkins C, Walters BAJ \& Schatell D (2002) Hemodialysis patients' symptom experiences: effects on physical and mental functioning. Nephrology Nursing Journal 29, 562574.

Johansen KL, Chertow GM, Ng AV, Mulligan K, Carey S, Schenfeld PY \& Kent-Braun JA (2000) Physical activity levels in patients on hemodialysis and healthy sedentary controls. Kidney International 57, 25642570.

Painter P, Carlson L, Carey S, Paul S \& Myll J (2000) Physical functioning and health related quality of life changes with exercise training in hemodialysis patients. American Journal of Kidney Disease 35, 482-92.

Periman RL, Finkelstein FO, Liu L, Roys E, Kiser M, Eisele G, Burrows-Hudson S, Messana JM, Levin N, Rajagopalan S, Port FK, Wolfe RA \& Saran R (2005) Quality of life in chronic kidney disease (CKD): a cross-sectional analysis in the Renal Research Institute-CKD study. American Journal of Kidney Diseases 45, 658-66.

Tawney KW, Tawney PJW \& Kovach J (2003) Disablement and rehabilitation in end-stage renal disease. Seminars in Dialysis 16, 447-452.

Thomas-Hawkins C (2000) Symptom distress and day-to-day changes in functional status in chronic hemodialysis patients. Nephrology Nursing Journal 27, 369-380, 428. 